\title{
Ejercicio de la patria potestad. Derecho de corrección de los padres y régimen de visitas. Posibilidad de actuación policial
}

\section{Exercise of parental authority. Parental rights to correct children, and visitation rights. Possibility of police action \\ Exercício da custódia. Direito de correção dos pais e regime de visitas. Possibilidade de ação policial}

\author{
Juan José Nevado Montero* \\ a Universidad Nacional de Educación a Distancia, España
}

- Fecha de recepción: 2019-08-28

- Fecha concepto de evaluación: 2019-11-04

- Fecha de aprobación: 2019-11-19 http://dx.doi.org/I0.22335/rlct.vI2il.1018
Para citar este artículo / To reference this article / Para citar este artigo: Nevado Montero, J. J. (2020). Ejercicio de la patria potestad. Derecho de corrección de los padres y régimen de visitas. Posibilidad de actuación policial. Revista Logos Ciencia \& Tecnología, I I (2),

| 64-174. http://dx.doi.org//0.22335/rlct.v|2il.1018

\section{RESUMEN}

En los ordenamientos jurídicos se reconoce como parte de la patria potestad, la facultad de los padres de corregir moderadamente a sus hijos y el derecho-deber de relacionarse con ellos en los casos de vida separada de los padres. El objeto del presente trabajo es analizar la configuración de los derechos de corrección y relación en diferentes ordenamientos latinoamericanos y compararlo con el español, estudiando cómo puede concretarse la actuación policial como autoridad llamada a colaborar con los padres, así como perfilar la actuación policial ante los incumplimientos del régimen de relación con los menores. Para ello se utilizará el método comparativo entre legislaciones. Se concluye que la regulación del derecho de corrección varía según el país, al igual que el incumplimiento del régimen de relación, que algunos países consideran delito y otros dirigen al orden civil.

Palabras clave: relación padres-hijos, educación familiar, aplicación de la ley, abuso de menores 


\section{SUMMARY}

As part of 'parental authority', the legal system recognizes the parents' power to moderately correct their children and their right-obligation to interact with them in cases where parents are separated. The purpose of this paper is to analyze the configuration of the parental rights to correct, as well as their rights to visitation in different Latin American ordinances, making a comparison with Spain, while studying how police, as the called upon authority, can collaborate with parents, as well as outlining the actions that police should take when confronted with breaches of visitation rights with minors. For this, the comparative method between laws will be used. It is concluded that the regulation of parental rights to correct varies between countries, as does the breach of visitation rights, which some countries consider to be a crime, while others consider it civil order.

Keywords: parent-child relationship, family education, law enforcement, child abuse

\section{SUMÁRIO}

A lei reconhece como parte dos direitos dos pais, o poder de corrigir moderadamente seus filhos e o direito-dever de se relacionar com eles em casos de separação dos pais. $O$ objetivo deste artigo é analisar a configuração dos direitos de correção e relacionamento em diferentes ordenamentos latino-americanos e compará-los com o espanhol, estudando como a ação policial pode concretizarse como uma autoridade chamada para colaborar com os pais, bem como alinhar a atuação policial diante de violações do regime de relacionamento com menores. Para isso, será utilizado o método comparativo entre leis. Conclui-se que a regulamentação do direito de correção varia de acordo com o país, assim como a violação do regime de relacionamento, que alguns países consideram crime e outros dirigem à ordem civil.

Palavras-chave: relação pai-filho, educação familiar, aplicação da lei, abuso infantil

La familia del derecho romano-francés aunó tanto a Latinoamérica a Castilla y Portugal, entre otras muchas culturas. De México a Argentina, hasta España y parte de Europa, compartimos no solo una lengua común, sino también ordenamientos, doctrina, y práctica del derecho (Hinestrosa, 2013).

Por otra parte, la patria potestad es un concepto jurídico de orden público, como institución básica de la estructura familiar, que al derivar de la filiación tiene idénticos caracteres que los estados civiles de la persona y, por tanto, es intransmisible, irrenunciable e imprescriptible (Acedo, 2013).

En este punto, Lasarte (2018) la define como el conjunto de deberes, atribuciones $y$ derechos que los progenitores ostentan respecto de los hijos que, por ser menores de edad, se encuentran de forma natural bajo la guarda, protección y custodia de sus padres, y Valencia (1995) como un elemento de las relaciones familiares y lineamiento esencial a partir del cual se hacen efectivos los derechos y expectativas de los progenitores en el cumplimiento integral que tienen para con sus hijos no emancipados.
Desde el punto de vista de la jurisprudencia, el Tribunal Supremo español lo ha configurado en la actualidad, como conjunto de derechos-deberes de los padres sobre sus hijos no emancipados y sus bienes; institución concebida al servicio del hijo, dirigida a prestarle la asistencia del artículo 39.3 de la Constitución española (Sentencia del Tribunal Supremo 720/2002, Sala I, de 9 de julio de 2002. Id Cendoj 28079II00I2002102369). A su vez, la Corte Constitucional de Colombia la define como la función especialísima capaz de garantizar el cumplimiento de los deberes de los padres mediante el ejercicio de determinados derechos sobre la persona de sus hijos y sobre sus bienes, siendo su finalidad el bienestar emocional y material de los menores no emancipados (Sentencia T-53I/92, de la Corte Constitucional, de 23 de septiembre de 1992).

Cualquier decisión judicial tomada en lo referente a la patria potestad, ha de salvaguardar el interés superior de la infancia y adolescencia, de conformidad con la CDN (Convención sobre los Derechos del Niño, adoptada por la Asamblea General de las Naciones Unidas el 20 
de noviembre de 1989. Instrumento de ratificación del 30 de noviembre de 1990. BOE 313 de 31 de diciembre de 1990) y sus artículos 3.I, 9 y 18.1. Así, ha establecido el Tribunal Supremo (TS), por todas, en la Sentencia del Tribunal Supremo (STS) 7/3/1996, de 17 de septiembre de 1996 (STS 7I3/1996, Sala I, de 17 de septiembre de 1996. Id Cendoj 28079 I I00 I I996 I0 I840), consagra:

el interés superior del menor como principio inspirador de todo lo relacionado con él, que vincula al juzgador, a todos los poderes públicos e, incluso, a los padres y ciudadanos, con reconocimiento pleno de la titularidad de derechos en los menores de edad y de una capacidad progresiva para ejercerlos, de manera que han de adoptarse aquellas medidas que sean más adecuadas a la edad del sujeto, para ir construyendo progresivamente el control acerca de su situación personal y proyección de futuro, evitando siempre que el menor pueda ser manipulado, buscando, por el contrario, su formación integral y su integración familiar y social, de manera que las medidas que los jueces pueden adoptar se amplían a todo tipo de situaciones, incluso aunque excedan de las meramente paternofiliales, con la posibilidad de que las adopten al inicio, en el curso o después de cualquier procedimiento conforme las circunstancias cambien y oyendo al menor.

En el mismo sentido, la jurisprudencia chilena establece la sumisión de los roles parentales a los derechos de los niños (Corte de Apelaciones de Antofagasta, causa Rol 204-2005, de $1^{\circ}$ de septiembre de 2005).

El interés superior del niño o favor filii, además de la CDN, se recoge en la resolución del 29 de mayo de 1987, del Consejo Económico y Social de las Naciones Unidas, que estableció que en todo caso el interés de los hijos debía ser la consideración primordial y, más concretamente, en los procedimientos relativos a su custodia, y en la resolución del Consejo de Europa en la Convención sobre el reconocimiento y ejecución de decisiones en materia de guardia de niños y el restablecimiento de la guardia de niños, de 1980, que determina que la institución de medidas destinadas a facilitar el reconocimiento y la ejecución de decisiones concernientes a la guardia de un niño ha de tener por efecto asegurar una mejor protección del interés de los niños.

El interés del menor está definido en algunos ordenamientos, como el argentino, donde se considera la máxima satisfacción, integral y simultánea de los derechos y garantías contemplados en la ley (art. 3 de la Ley 26.06I, sobre protección integral de niñas, niños y adolescentes), o el colombiano, como el imperativo que obliga a todas las personas a garantizar la satisfacción integral y simultánea de todos sus derechos humanos (art. 80 de la Ley 1098, de 8 de noviembre de 2006). Pero otros, como el español, no lo definen, sino que obligan a valorarlo y considerarlo como primordial en todas las acciones y decisiones que conciernan al niño, tanto en el ámbito público como el privado (art. 2 de la Ley Orgánica I/I996, de 15 de enero, de Protección Jurídica del Menor, de modificación parcial del Código Civil y de la Ley de Enjuiciamiento Civil), al igual que hace la norma peruana (art. 9 de la Ley 27337, del Código de los Niños y Adolescentes). El colombiano obliga a interpretar las normas de su código velando por el interés superior (art. 6 de la Ley 2026, del Código del Niño, Niña y Adolescente), y en Chile se establece como preocupación principal de los padres (art. 222 del Código Civil chileno).

Romero (20I0) destaca que ese término no es demasiado afortunado porque parece delatar un cierto aire mercantilista, pues "interés" denota provecho, utilidad o ganancia, y "beneficio", el bien que se hace, o se recibe, o también utilidad y provecho. Ella propone referirse al "bienestar" del hijo menor de edad, pues considera que es un concepto más amplio, de comprensión más sencilla, y que abarca todas las conductas, actitudes y comportamientos que redundan en beneficio del hijo y que hacen referencia al mejor y más completo desarrollo de su personalidad.

En cuanto a los caracteres mencionados de la patria potestad, la intransmisibilidad deriva de que nace con la filiación, y se encuentra fuera del comercio, por lo que no puede cederse, aunque ciertos aspectos pueden delegarse; por ejemplo, cuando un menor asiste a clase en un internado, o cuando permanecen bajo el cuidado de familiares durante una temporada. La patria potestad la siguen ostentando los padres, pero se valen de un tercero para ejercer parte de las funciones (García, 2013). De igual forma, aunque no ejerzan la patria potestad, hay sujetos que pueden influir con sus actuaciones en dicho ejercicio (el juez o fiscal, la nueva pareja de un progenitor separado en determinados ordenamientos, etc.).

Su irrenunciabilidad trae causa de su imposición por la ley, sin que se contemple la dejación voluntaria de las tareas que comprende; es más, algunas obligaciones en ella contenidas, como el deber de prestar alimentos permanecen, aunque los padres se vean privados de ella. 
La intransmisibilidad y la irrenunciabilidad hacen que no pueda perderse por el paso del tiempo, por lo que es imprescriptible.

El presente estudio se justifica si se tienen en cuenta los datos que proporciona el Ministerio de Sanidad, Consumo y Bienestar Social español (www.infanciaendatos.es), que demuestran que la población de menores de II a 18 años que puede hablar de sus problemas con su familia es del $44,2 \%$, sin que existan apenas diferencias entre sexos, pero sí entre edades, observándose que en la franja de edad de $1 \mathrm{I}$ a 16 años únicamente pueden hacerlo una media del $35 \%$, y solo en la franja entre 16 y 18 años lo hacen el $65 \%$, posiblemente porque la mayor madurez posibilita la mayor capacidad de comunicación e interacción.

\section{El derecho de corrección}

En el derecho romano originario o quiritario, el paterfamilias ostentaba la facultad de infligir al hijo toda suerte de castigos e incluso la muerte, atenuándose durante la época imperial, cuando se redujo a una simple potestad correccional. Esta disminución también se dio en el derecho germánico (Castán, 1960). En la normativa histórica española, en las Partidas, el padre tiene consagrado un derecho de corrección siempre correlativo al deber de educación de sus hijos, por lo que el castigo ha de hacerlo con mesura y piedad, pues de lo contrario podría perder la patria potestad (Alfonso X, Cuarta partida, título I8, leyes $7,8,9$ y 18$)$.

El profesor Lasarte (20I8) considera el derecho de corrección como una consecuencia natural de la función de educación de los padres respecto a los hijos, pues sobre todo en edades tempranas y con cariz orientador de la conducta, el premio y el castigo pueden formar parte de la relación paternofilial.

La evolución del precepto constata que la historia de la patria potestad constituye, en conjunto, un proceso de debilitación de la autoridad parental. Concebida antiguamente como un poder sobre los hijos ejercido por los padres, la patria potestad ha pasado a ser contemplada como un servicio, es una potestad en sentido estricto de los padres en beneficio de los hijos; función cuyos actos deben estar dominados y encaminados, siempre, al interés del menor, como se ha indicado.
En la redacción original del Código Civil español, el padre, y en su defecto la madre, tenían la facultad de corregir y castigar moderadamente a sus hijos no emancipados, pero tras la promulgación de la Constitución española de 1978, la Ley II//98I, de 13 de mayo, de modificación del Código Civil en materia de filiación, patria potestad y régimen económico del matrimonio, en aplicación del principio de igualdad de ambos padres en el ejercicio de la patria potestad, modificó el artículo, y eliminó la palabra "castigar", por lo que pasó a contemplarse únicamente la corrección razonable y moderada.

Esa facultad se mantuvo en el derecho español hasta la publicación de la Ley 54/2007, de 28 de diciembre, de adopción internacional, en cuya exposición de motivos explica que dado el vínculo de unión de la adopción con la protección de menores, aprovecha para la modificación del artículo 154 del Código Civil, pues el Comité de los Derechos del Niño había mostrado su preocupación por la posibilidad de que la facultad de corrección moderada pudiera contravenir el artículo 19 de la CDN, que España había ratificado. La modificación eliminó cualquier referencia a la corrección, siendo el tenor actual del precepto: "Los progenitores podrán, en el ejercicio de su función, recabar el auxilio de la autoridad".

Sí que persiste la facultad de corrección en los derechos forales de algunas comunidades autónomas españolas (art. 65.l.d del Código de Derecho Foral de Aragón, Ley 65 de la Compilación de Derecho Civil Foral de Navarra, y art. 236. 17.4 del Código Civil de Cataluña), y siendo las normas aragonesa y catalana posteriores al 2007, llama la atención que no hayan contemplado los mandatos de orden internacional que prohíben el castigo corporal a los menores (Pous, 20I4).

A pesar de la eliminación en el Código Civil español del derecho de corrección, Pous (2014) considera basándose en las aportaciones doctrinales y resoluciones judiciales dictadas en la materia, que el derecho de corrección sigue actualmente en vigor. La autora señala que las relaciones entre padres e hijos están presididas por los vínculos afectivos, por ello en muy pocas ocasiones se ha de acudir a la regulación legal de derechos y obligaciones. Que las obligaciones de los hijos hacia los padres son menores, pues frente al elenco de deberes parentales, a los hijos únicamente se les impone la obediencia y respeto filial a los padres y la contribución a las cargas familiares 
mientras convivan en el hogar familiar. Concluyendo, que al estar unida la facultad de corrección al deber de educación, y habiendo deber de obediencia de los hijos, es natural que la falta de este pueda conllevar una sanción correctiva de los padres.

Algarra y Barceló (2016) también opinan que a pesar de la reforma, los padres ostentan el derecho de corrección respecto de sus hijos por varias razones. En primer lugar, porque de forma tradicional el derecho español ha reconocido a los padres la facultad de corrección, manteniéndose en la actualidad en algunos derechos forales, por ello no puede considerarse un vestigio histórico $o$ anticuado de posible eliminación. En segundo lugar, doctrinalmente se ha considerado que el derecho-deber de corrección está ligado de forma íntima al derecho-deber de educación, todavía vigente en la patria potestad. En tercer lugar, entienden que solicitar el auxilio de la autoridad debe ser una medida excepcional y subsidiaria, de posible utilización en situaciones de cierta gravedad, pero que no puede sustituir a la facultad de corrección de los padres. En cuarto lugar, ante la exigencia de obligaciones de los hijos, la falta de obediencia de los hijos podría implicar la facultad de corrección de los padres y la posibilidad de exigir su cumplimiento. Finalmente, y con fundamento en la no aplicación de sanciones civiles y penales en supuestos de correctivos físicos de escasa entidad, concluyen que hay que aceptar que persiste el derecho de corrección, y las reformas solo han pretendido eliminar cualquier resquicio que pudiera permitir un castigo físico, aunque con ello se haya debido suprimir cualquier otra modalidad de corrección.

También se mantiene la facultad de corrección en la mayoría de las normativas latinoamericanas, si bien con referencia expresa a la moderación (art. 143 del Código de Familia de Costa Rica, art. 86 del Código de Familia de Cuba, art. 215 del Código de Familia de El Salvador, art. 319 del Código de Familia de Panamá).

El Código Civil de Chile también contempla el derecho de corrección, y es el único que en su artículo 234 detalla de forma expresa que la facultad de corrección deberá ejercerse en conformidad con la ley a la CDN.

Sin embargo, Honduras, Uruguay y Venezuela lo prohíben. El Código de Familia de Honduras (art. 19174) veta la utilización del castigo físico, o cualquier tipo de trato humillante, degradante, cruel o inhumano, como forma de corrección o disciplina de niños. Idéntico tenor tienen el artículo 12-bis del Código de Niñez y Adolescencia de Uruguay, y el 32 de la Ley Orgánica para la Protección de Niños, Niñas y Adolescentes de Venezuela.

Y Argentina, como España, prohíbe el castigo corporal en cualquiera de sus formas, los malos tratos, y cualquier hecho que lesione o menoscabe física o psíquicamente a los niños o adolescentes, posibilitando a los progenitores solicitar el auxilio de los servicios de orientación a cargo de los organismos del Estado.

En aquellos países donde se prohíbe de forma taxativa a los padres corregir la conducta de los hijos, cabría preguntarse cómo atajar las faltas de disciplina propia de niños y jóvenes que de no eliminarse pueden ir a mayores con la edad.

Y en los lugares como Argentina o España, donde se dirige a los padres a solicitar la ayuda del Estado (en España de la autoridad), habría que plantearse si se debe de llamar a la policía cuando los niños se nieguen a levantarse para ir al colegio, se nieguen a comer o bajar los pies de la mesa, etc. (Lasarte, 20I8).

Como se indicó, el presente trabajo se centra únicamente en la posibilidad de actuación policial en caso de mala conducta de los menores, sin abarcar la comisión de delitos u otras situaciones, como los malos tratos o violencia familiar.

En el ámbito policial, la relación con la comunidad se ha convertido en uno de los elementos centrales (Dammert, 2005), y la mayoría de las instituciones policiales han adoptado protocolos de actuación encaminados a intervenir en la solución de conflictos entre las personas fruto de la convivencia (molestias por distintas causas, discrepancias en cuanto a la utilización de espacios públicos, etc.).

Esas directrices de actuación para los distintos cuerpos policiales se adecuan a la distribución de competencias en cada país. En el caso español, cuando se promulgó la Constitución española de 1978, se reservó para el Estado la regulación de la obtención, expedición y homologación de títulos académicos y profesionales y las normas básicas para el desarrollo del derecho a la educación, y se posibilitó que las comunidades autónomas asumieran las competencias en asistencia social. 
Con ese desarrollo del estado de las autonomías, todas las comunidades $y$ entidades locales (ayuntamientos) han asumido las competencias en educación y servicios sociales, de forma que las actuaciones en prevención del absentismo escolar y conflictos en el ámbito familiar son atendidas por las policías de cada municipio (policías locales o municipales), sin que intervengan, por lo general, las de carácter nacional (Cuerpo Nacional de Policía y Guardia Civil), centradas en la salvaguarda de la seguridad ciudadana en todas sus vertientes.

En la actualidad, la escolarización obligatoria en España se extiende hasta los 16 años (desde 1990), al haberse aumentado la vigente anteriormente, 14 años, para hacerla concordante con la edad mínima para incorporarse a un puesto de trabajo. En la actuación en el ámbito familiar por problemas conductuales de los menores, además de la labor realizada in situ, centrada en informar al menor del deber de obediencia a los padres establecido en todos los ordenamientos, $y$ en convencerle para acatar las normas de convivencia de la unidad familiar establecidas por quienes ostentan la patria potestad, de forma que le sea comprensible en función de su edad y desarrollo, deben realizarse las pesquisas oportunas a fin de detectar si existe algún signo de desprotección infantil, con el objetivo de notificarlo al organismo competente para su trámite.

Normalmente, esos organismos serán los servicios sociales, existentes hoy en día en todos los países tanto de Europa como de Latinoamérica. Un escollo importante es la inexistencia de servicio ininterrumpido en los servicios sociales, problema más común en pequeños municipios, motivo por el que es recomendable prever dicha circunstancia por parte de la administración policial, de forma que pueda garantizarse la continuidad de la atención cualquier día a cualquier hora.

En la actualidad existen en países como España o Argentina los Centros de Atención a la Mujer especializados en la actuación en el ámbito de la violencia doméstica, pero no resultan adecuados para el tratamiento de los problemas objeto del presente trabajo, centrado en las anomalías conductuales, no en el delito. Estos centros funcionan las 24 horas del día, y suelen contar con todos los medios necesarios (como ejemplo, en algunos lugares de España están dotados de intérpretes de lengua de signos).

A mi juicio, es aconsejable remitir la notificación a los servicios sociales de forma inmediata si se observan indicios de desprotección, pues la dilación para la obtención de pruebas concluyentes puede implicar una situación de riesgo para los menores, aunque si en la primera actuación se constatara alguna situación urgente, como el maltrato u abandono, la actuación policial para evitar el daño a los niños sería previa a la notificación.

Son varios los indicadores de desprotección que pueden ser observados en la intervención policial motivada por la mala conducta del menor, y que se obtienen de la experiencia propia en la labor policial, entre ellos:

- La mendicidad infantil, cuando no constituya delito.

- La presencia de niños en la calle durante el horario escolar.

- La presencia de niños en la calle a horarios inadecuados sin supervisión de adultos.

- Las conductas antisociales como hurtos, consumo de estupefacientes, etc.

Por ello, desde mi punto de vista, y con fundamento en la experiencia de actuaciones policiales, el atestado que se redacte deberá contener todos aquellos detalles que faciliten el trabajo de los servicios sociales, siendo de especial interés:

- La identificación de todos los miembros de la unidad familiar, con la información obrante en los archivos policiales sobre actuaciones anteriores, y los medios de localización de los padres, haciendo referencia, si es posible, a sus medios de vida.

- La descripción de los indicadores de desprotección observados, recogiendo con detalle el motivo de la actuación, el estado físico y anímico de los implicados, y si se ha producido en el interior del domicilio las condiciones de habitabilidad del mismo (con descripción de número de habitaciones, cuartos de baño, disponibilidad de electricidad, agua caliente, estado de limpieza, etc.).

Después de la notificación, y sin perjuicio de la actuación de los servicios sociales, resulta esencial, en coordinación con estos, planificar el seguimiento ulterior de la situación, pues los cuerpos policiales, por su actuación a pie de calle, pueden observar, de forma más directa que el resto de los profesionales, la conducta de las personas usuarias del tratamiento, debiendo informar puntualmente de cualquier incidente.

Como conclusión en lo atinente al ejercicio del derecho de corrección por los padres, podemos señalar que existen tres posturas: la de aquellos estados donde se mantiene, si bien, y en armonía con la concepción actual de la pa- 
tria potestad, debe llevarse a cabo con moderación; aquellos donde está prohibido de forma terminante; $y$ aquellos donde puede invocarse la colaboración del Estado.

La opinión sobre cuál será el sistema que mejor salvaguarda el interés de los menores, queda al libre pensamiento de cada uno de los lectores, pues todas las opciones tienen sus pros y sus contras. Desde la perspectiva intervencionista, podría argumentarse la necesidad de actuar por parte de las instituciones como garantía de indemnidad del bienestar de los niños, primando ese derecho sobre la intimidad familiar; pero desde el punto de vista liberal se podría argumentar que el derecho al libre desarrollo de la persona no puede verse constreñido por la intervención de extraños a la familia ante un pequeño problema por la conducta inadecuada de un menor, en el entendido de que la actuación estaría plenamente justificada si se observara una situación grave.

\section{El incumplimiento del régimen de relación con los hijos menores}

Otras de las situaciones comunes de actuación de los cuerpos policiales son las derivadas de los incumplimientos de los regímenes de guarda y custodia o de relación, establecidos tras la crisis de pareja, por parte de los progenitores.

En la vida diaria de algunas personas supone un problema la difícil conciliación de la vida laboral y familiar, y hay menores que se ven privados de la compañía de sus padres tras finalizar su jornada escolar, acudiendo a su hogar, en el que están solos parte de la tarde, con el consiguiente descuido en ocasiones de las tareas escolares por la falta de atención de sus progenitores (García, 20I3).

Pero la verdadera quiebra se produce cuando cesa la vida en común de los padres, contemplándose en la resolución judicial que regule la nueva situación (para el caso de que se ventile el asunto ante los tribunales), la distribución de tiempos en que cada uno tendrá a los niños en su compañía.

En estos casos, la ruptura de las relaciones de pareja causa una modificación en la vida del núcleo familiar, pues la obligación de los padres de tener a los hijos en su compañía, tendrá que hacerse compatible con la nueva situación de falta de convivencia.

En el ámbito internacional, la Convención sobre los Derechos del Niño (CDN) establece, en su artículo 9.3:
"Los Estados Partes respetarán el derecho del niño que esté separado de uno o de ambos padres a mantener relaciones personales y contacto directo con ambos padres de modo regular, salvo si ello es contrario al interés superior del niño".

Con carácter previo al estudio de los incumplimientos, conviene distinguir entre lo que Acuña (2014) denomina supuestos de no ejercicio del derecho, motivados por hechos no previstos por los progenitores o el juez, como accidentes o enfermedades graves, cambios de residencia por motivos laborales, ingreso en prisión de uno de los padres, etc., y los incumplimientos propiamente dichos, que constituyen inobservancias deliberadas de lo establecido en la resolución que regula las visitas.

En el primer caso, si la situación es transitoria (enfermedad) sería suficiente con comunicar los hechos que impiden las visitas y acordar cómo superarlos, y si puede consolidarse y devenir permanente (traslado de residencia), deberá de modificarse la resolución judicial para adaptar el régimen de visitas a las nuevas condiciones.

Estos incumplimientos pueden afectar tanto a la cantidad como a la calidad de las visitas, pues no siempre, aunque se respeten los días y horarios, se desarrollan de forma que salvaguarden el bienestar de los niños.

Es de destacar que no únicamente los padres pueden solicitar la intervención de la policía ante un incumplimiento del régimen de relación, pues pueden ser titulares del derecho otras personas. En Chile se incluye a otros parientes (art. 48 de la Ley de Menores, modificada por la Ley 19.7II); en España, a otros parientes y allegados (art. 160 del Código Civil),y en Argentina, algunos autores defienden la tesis de la interpretación amplia del artículo 376 del Código Civil, entendiendo concedido el derecho no solo al progenitor que no detenta el cuidado personal, sino también a otros parientes y terceros con quien el menor tenga lazos afectivos (Quintana, 2009).

La actuación policial motivada por los incumplimientos tiene lugar en los sitios donde habitualmente se establece el inicio o final de las visitas, que son el centro escolar o el domicilio de alguno de los progenitores.

El incumplimiento tiene consecuencias diferentes dependiendo del país (Truffello, 2017).Analizaremos de forma sucinta las regulaciones en Chile, Argentina, Perú, Colombia y España. 
En Chile se sanciona con la suspensión o restricción del régimen de relación, arresto, multa, o prescindir de la autorización de salida al extranjero del menor, debiendo recuperarse el tiempo de relación perdido (Ley 16.618 de Menores. Art. 48, inc. 4. "El padre o madre que incumpla injustificadamente el régimen comunicacional fijado, puede ser instado a cumplirlo bajo apercibimiento de decretar su suspensión o restricción". Art. 48, incs. 4 y 66 . "En la misma hipótesis anterior, el padre o madre infractor puede ser apremiado con arresto de hasta por 15 días o multa proporcional, sanciones contempladas en el artículo 543 del Código de Procedimiento Civil, en materia de cumplimiento del procedimiento ejecutivo". Arts. 49 y 49 bis. "El juez puede autorizar la salida del país del niño prescindiendo de la autorización del padre o madre no custodio que incumplió el régimen comunicacional con su hijo/a. En efecto, puede autorizar a quien ejerza el cuidado personal del niño a salir de país con este, en distintas ocasiones dentro de los dos años siguientes, por un plazo no superior a los quince días, siempre que se acredite el incumplimiento injustificado del régimen comunicacional regulado a favor del otro progenitor").

En Argentina se pena con prisión. La Ley 24270 tipifica como delito la conducta de un padre o tercero que impida u obstruya el contacto de menores de edad con sus padres no convivientes, castigándolo con prisión de un mes a un año, o de seis meses a tres años si el niño es menor de diez años o se encuentra en situación de discapacidad. Se castiga con la misma pena el cambio de domicilio para impedir la relación del otro progenitor con el menor, incrementándose si el traslado se realiza al extranjero. Es un delito privado (art. 72.3, Código Penal argentino), iniciándose el procedimiento por acusación o denuncia del agraviado, tutor, guardador o representante legal.

En Perú, el Código de los Niños y Adolescentes establece que el padre o la madre que haya sido impedido o limitado de ejercer el derecho de visita, puede interponer la demanda correspondiente (art. 98), siendo consecuencia del incumplimiento los apremios de la ley y en caso de resistencia la variación de la tenencia del hijo.

En Colombia, el Código de la Infancia y la Adolescencia contiene medidas de restablecimiento del régimen de visitas. Se recoge la amonestación o conminación a los padres o responsables del cuidado del niño, y la orden perentoria de que cesen las conductas que puedan vulnerar o amenazar los derechos del menor, obligando a asistir a un curso sobre derechos de la niñez, bajo pena de multa convertible en arresto. Si se incumplen las obligaciones impuestas en la amonestación, se sanciona con multa equivalente al valor de uno a cien salarios mínimos diarios legales vigentes, convertibles en arresto de un día por cada salario diario mínimo legal vigente de multa (art. 55).

$Y$ en España, el incumplimiento del régimen de visitas era constitutivo de infracción penal, por ello, tenía sentido que el progenitor afectado requiriera la presencia de la policía en el lugar donde debía de realizarse el intercambio de los menores. De esa manera, los agentes de la autoridad podían identificar al progenitor y plasmar en un atestado donde se encontraba y a qué hora, y además, reflejar si en la vivienda donde los niños debían ser recogidos o entregados respondía alguien al llamar a la puerta, y en su caso, identificar al presunto incumplidor. Siendo testigos del delito, su declaración resultaba clave en el procedimiento penal, $y$ estaban obligados a intervenir en su labor de averiguación delictiva.

Con la despenalización en el 2015 del incumplimiento del régimen de visitas, la intervención de la policía deja de tener sentido según algunos órganos del Estado, al ser el incumplimiento un conflicto a enjuiciar en el orden civil.

En este sentido, y como respuesta a la consulta de un padre sobre la actuación policial ante los incumplimientos de entrega de menores, la Subdelegación del Gobierno de Burgos (España) recabó un informe de la abogacía del Estado, y respondió en escrito fechado el 23 de mayo de 2017, que la policía carece de competencias en materia de control de convenios reguladores de medidas parentales, siendo dicho control competencia exclusiva de los órganos judiciales. Además, concluye que entre las funciones de las fuerzas y cuerpos de seguridad no se encuentra la de actuar como testigos en procesos, pudiendo el afectado promover un acta de notoriedad para hechos notorios que afecten a las relaciones personales que desea acreditar.

De esta manera, la despenalización traslada la carga probatoria al afectado por el incumplimiento, pues cuando era considerado delictivo la policía podía dar razón del incumplimiento con su presencia, pero actualmente lo harán en unas ocasiones y en otras no, pues consultados varios mandos de las fuerzas y cuerpos de seguridad españolas: Cuerpo Nacional de Policía, Guardia Civil y policías locales (consultas realizadas, ad hoc, por el autor en mayo de 
2019 en la Jefatura Superior del Cuerpo Nacional de Policía de Valencia, Comandancia de la Guardia Civil de Valencia, y Central de Policía Local de Valencia), manifestaron que no tenían una directriz clara al respecto, sin que conocieran el escrito de la Subdelegación del Gobierno de Burgos al que se ha hecho referencia, y que la atención o no de los agentes dependería normalmente del funcionario policial que recibiera el aviso.

La intervención policial estaría justificada en cualquier caso. No es necesario mayor comentario para el caso de los países donde los incumplimientos se tipifican como delito, pues será necesario recoger los hechos en un atestado y trasladarlo a la autoridad judicial. Pero en los países donde no constituye delito, considero igualmente necesaria la actuación, pues como se explica a continuación, los incumplimientos pueden considerarse en determinadas circunstancias como delito de desobediencia a la autoridad judicial, además de poder constituir un perjuicio para el niño, a quien se le priva de la compañía de un progenitor, pudiendo ser de utilidad la alegación de lo ocurrido en un procedimiento de modificación de medidas por cambio de las circunstancias.

A modo de ejemplo, trataremos la posibilidad de considerar delito el incumplimiento reiterado del régimen de relación en el ordenamiento de España.

Actualmente, salvo en casos excepcionales, no será posible incardinar en el tipo del artículo 226 del Código Penal español los incumplimientos del régimen de visitas, pues este recoge los supuestos de abandono de familia por dejar de prestar los deberes legales de asistencia inherentes a la patria potestad, o de prestar la asistencia necesaria para el sustento, pero quedaría dentro del orden penal el recurso al artículo 556 ("Serán castigados con la pena de prisión de tres meses a un año o multa de seis a dieciocho meses, los que, sin estar comprendidos en el artículo 550, resistieren o desobedecieren gravemente a la autoridad o sus agentes en el ejercicio de sus funciones, o al personal de seguridad privada, debidamente identificado, que desarrolle actividades de seguridad privada en cooperación y bajo el mando de las Fuerzas y Cuerpos de Seguridad. Los que faltaren al respeto y consideración debida a la autoridad, en el ejercicio de sus funciones, serán castigados con la pena de multa de uno a tres meses"), donde puede encuadrarse la desobediencia a las resoluciones judiciales en lo que atañe al cumplimiento de dichas medidas establecidas en la sentencia.
El tipo del artículo 556 requiere para ser aplicado que se trate de un quebrantamiento grave (así lo recuerda en su Fundamento de Derecho Segundo la STS 870/2015, de 19 de enero. Id Cendoj 8079I200I20I6I000I0), considerando la gravedad un elemento abierto del tipo que exige una valoración del hecho acorde con su entidad en relación con el bien jurídico protegido.

Además, la aplicación del artículo 556 está supeditada a que concurran y se acrediten todos y cada uno de los requisitos del tipo penal, a tenor de la STS 1615/2003, de $I^{\circ}$ de diciembre. Id Cendoj 28079I200I2003 I00029:

- La preexistencia de una orden legítima de la autoridad competente que sea de obligado cumplimiento.

- El conocimiento de esa orden por el interesado.

- La conducta omisiva de este, que la desatiende y no la cumple. Se colma la tipicidad de la desobediencia cuando se adopta una reiterada y evidente pasividad a lo largo del tiempo y no se da cumplimiento al mandato.

Sobre la necesidad de que se cumplan estos requisitos resulta ilustrativo el Auto de la Audiencia Provincial (AAP) León 94I/2017, de 5 de septiembre, Id Cendoj 24089370032017200937, que confirma un Auto de un juzgado que decretaba el sobreseimiento de un procedimiento penal iniciado por el incumplimiento del régimen de visitas que atribuyó al autor un delito de desobediencia.

El Auto expone que actualmente las únicas vulneraciones del derecho de visitas que resultan punibles son las cometidas por terceros no progenitores, previstas en el artículo 223 del Código Penal (Art. 223. "El que, teniendo a su cargo la custodia de un menor de edad o una persona con discapacidad necesitada de especial protección, no lo presentare a sus padres o guardadores sin justificación para ello, cuando fuere requerido por ellos, será castigado con la pena de prisión de seis meses a dos años, sin perjuicio de que los hechos constituyan otro delito más grave"), sin que la conducta obstructiva 0 abiertamente rebelde al régimen judicial por parte de un progenitor pueda ser sancionada de otro modo que a través del delito de sustracción de menores del artículo 225 bis (Art. 225 bis. "I. El progenitor que sin causa justificada para ello sustrajere a su hijo menor será castigado con la pena de prisión de dos a cuatro años e inhabilitación especial para el ejercicio del derecho de patria potestad por tiempo de cuatro a diez años. 2.A los efectos de este artículo, se considera sustracción: I. El traslado de un menor de su lugar de residencia sin consentimiento del progenitor con quien 
conviva habitualmente 0 de las personas o instituciones a las cuales estuviese confiada su guarda o custodia. 2 . La retención de un menor incumpliendo gravemente el deber establecido por resolución judicial o administrativa. 3. Cuando el menor sea trasladado fuera de España o fuese exigida alguna condición para su restitución la pena señalada en el apartado I se impondrá en su mitad superior. 4. Cuando el sustractor haya comunicado el lugar de estancia al otro progenitor o a quien corresponda legalmente su cuidado dentro de las veinticuatro horas siguientes a la sustracción con el compromiso de devolución inmediata que efectivamente lleve a cabo, o la ausencia no hubiere sido superior a dicho plazo de veinticuatro horas, quedará exento de pena. Si la restitución la hiciere, sin la comunicación a que se refiere el párrafo anterior, dentro de los quince días siguientes a la sustracción, le será impuesta la pena de prisión de seis meses a dos años. Estos plazos se computarán desde la fecha de la denuncia de la sustracción. 5 . Las penas señaladas en este artículo se impondrán igualmente a los ascendientes del menor y a los parientes del progenitor hasta el segundo grado de consanguinidad o afinidad que incurran en las conductas anteriormente descritas"), cuyos elementos objetivos y subjetivos no se daban en el caso de autos, o a través de la figura del delito de desobediencia del artículo 556.

Y respecto a la reconducción al delito de desobediencia establece, que si bien no incluye, según la más reciente doctrina jurisprudencial, la prevención al destinatario de una orden judicial de la posibilidad de incurrir en responsabilidad criminal en caso de apartarse de su tenor, sí exige tal orden judicial, personalizada en el sujeto al que luego se dirige el reproche de responsabilidad criminal.

Además, considera que la necesidad de gravedad en el artículo 556 impide que la criminalidad de la conducta obstativa pueda ser apreciada después de un único fin de semana o turno de visitas.

En el caso de autos no constaba que se hubiera realizado requerimiento de cumplimiento al denunciado por parte de la autoridad judicial, pues únicamente se acreditó que el denunciante había comparecido ante agentes de la autoridad para exponer los incumplimientos, y los agentes no son personal jurisdiccional.

La Audiencia Provincial considera el sobreseimiento del procedimiento penal acorde a derecho, porque la conducta solo es grave bien por la persistencia en el incumplimiento, lo que requiere la constatación de más de un acto de desobediencia, o bien de la resistencia igualmente persistente del progenitor, posterior a un requerimiento o iniciativa del juzgado, dirigidos al mismo por el juez de familia, para que se abstenga de protagonizar conductas obstativas de las visitas entre el hijo común y el otro progenitor, con el correspondiente apercibimiento de poder incurrir en responsabilidad criminal; o bien la imposición de multas coercitivas por parte del letrado de la administración de justicia, que se revelasen inútiles de cara a la rectificación de la conducta después de un tiempo apreciable.

Por ello, como se ha indicado, estaría justificada la actuación policial, motivada por la presunta comisión de un delito de desobediencia a la autoridad judicial, siendo necesario reflejar en el atestado todas las circunstancias que puedan ser de utilidad para el enjuiciamiento: identificación de las partes, si muestran resolución judicial que recoja el régimen de guarda y custodia (haciendo constar el número y fecha de dicha resolución), día, hora y lugar de la actuación, y cómo se ha resuelto.

\section{Conclusiones}

Con el paso del tiempo, el ejercicio de la patria potestad ha cambiado de forma que la mayor intervención de los Estados ha supuesto una pérdida de poderes para los progenitores, que en la actualidad han de dirigir todos sus actos al interés de los menores.

El derecho de corrección de los padres hacia los hijos se mantiene en algunos Estados, si bien, y en armonía con la concepción actual de la patria potestad, debe llevarse a cabo con moderación (Costa Rica, Cuba, El Salvador, Panamá, Chile).

En otros países está prohibido de forma terminante (Honduras, Uruguay, Venezuela), y en otros está prohibido, pero puede invocarse la colaboración del Estado ante problemas de conducta de los niños (España).

En la intervención policial por problemas de conducta de menores, debe investigarse si existe algún indicio de desprotección, poniéndolo en conocimiento de los servicios sociales de forma inmediata, y coordinando con estos el seguimiento de la situación.

Los incumplimientos del régimen de relación de los progenitores con sus hijos se tratan de manera diferente en los distintos países. La actuación policial en los 
incumplimientos del régimen de relación está plenamente justificada allí donde se tipifique como delito, pero también donde no se contempla como tal, pues los incumplimientos graves y reiterados pueden ser constitutivos de delito de desobediencia a la autoridad judicial.

\section{Referencias}

Acedo,A. (20I3). Derecho de familia. Madrid: Dykinson.

Acuña, M. (20|4). Derecho de relación entre los hijos y el progenitor no custodio tras el divorcio. Madrid: Dykinson.

AlfonsoX.Las SietePartidas.Recuperadodehttps://www.boe.es/ publicaciones/biblioteca_juridica/publicacion.php?id=PUBLH-20I I-60_LAS_SIETE_PARTIDAS\&tipo=L\&modo=I. Consultado el 15 de mayo de 2019.

Algarra, E., \& Barceló, J. (2016). Libertad de los hijos en la familia: deberes de los hijos y derecho de corrección de los padres. Situación en el derecho español. Actualidad Jurídica Iberoamericana, 4, 59-64.

Castán, J. M. (1960). La patria potestad. Madrid: Revista de Derecho Privado.

Dammert, L. (2005). Reforma policial en América Latina. Quórum: Revista de Pensamiento Iberoamericano, 12, 53-64.
García, I. (20I3). La patria potestad. Madrid: Dykinson.

Hinestrosa, F. (2013). Derecho romano, tradición romanista y América Latina. Revista de Derecho Privado, 25, pp. 3-7.

Lasarte, C. (20I8). Principios de derecho civil. Tomo IV. Derecho de familia. Madrid: Marcial Pons.

Pous de la Flor, M. P. (20|4). La controvertida eliminación de la facultad de corrección de los progenitores. Revista Crítica de Derecho Inmobiliario, 743, I376-I40 I.

Quintana, M. S. (2009). Legislación y jurisprudencia sobre el cuidado personal del niño y la relación directa y regular con él. Revista de Derecho de la Pontificia Universidad Católica de Valparaíso, XXXIII, pp. I49- 172.

Romero, A. M. (2010). Incumplimiento del derecho de visitas y consecuencias jurídicas en el marco familiar. Madrid: Reus.

Truffello, P. (2017). Sanciones por incumplimiento de relación directa y regular entre padres e hijos. Chile y legislación extranjera. Recuperado de https://www.bcn.cl/obtienearchi vo?id=repositorio/I 022 I/24564/2/Informe_BCN_Sanciones_RDR\%20(I).pdf. Consultado el 20 de agosto de 2019.

Valencia, A. (1995). Derecho civil. Derecho de familia. Tomo V. Bogotá:Temis. 